\title{
Cruz en la Piedra. Apropiación selectiva, construcción y CIRCULACIÓN DE UNA IMAGEN CRISTIANA EN EL ARTE RUPESTRE ANDINO COLONIAL
}

\author{
Marco Antonio Arenas ${ }^{1}$ y Carolina Odone ${ }^{2}$
}

\section{* Planteamiento del problema}

Resumen

Se contextualiza la introducción de la imagen de la cruz latina en un proceso de conquista y colonización del imaginario indígena en los Andes del Sur. Se propone la ocurrencia de movimientos significantes desde el universo representacional cristiano a un universo andino, destacando movimientos de negación y/o apropiación selectiva del ícono de la cruz católica en el sistema del arte rupestre. Se destaca a este sistema como un lenguaje visual funcionando desde la cultura propia y en evidente conflicto con los lenguajes formales de la evangelización colonial.

Palabras claves: Cruz latina - arte rupestre - período colonial - apropiación selectiva - represión iconoclasta.

\begin{abstract}
The introduction of the image of the Latin cross as part of a process of conquest and colonization of indigenous imagery in the Andes is contextualized. The occurrence of a significant movement of the Latin cross is proposed from the Christian representational universe to the Andean universe, highlighting movements of denial and/or selective appropriation of the Catholic cross icon in the rock art system. This system stands as a visual language operating from their own culture and in obvious conflict with the formal languages of colonial evangelization.
\end{abstract}

Key words: Latin cross - rock art - colonial evangelization - denial and/ or selective appropriation.

Recibido: Marzo 2015. Aceptado: Octubre 2015
Hoy por hoy, la cruz cristiana es el ícono religioso más extendido en los Andes del Sur ${ }^{3}$. En distintas comunidades rurales, la cruz cristiana se levanta en el paisaje, en los atrios y portales de las iglesias, y en los caminos que circundan los poblados. Para festividades religiosas patronales o bien para la celebración de la Santa Cruz, cada tres de mayo, las gentes las pintan, visten y adornan; y para protegerse de los malos espíritus, pequeñas cruces se disponen en los techos de las casas. La presencia de este ícono remite evidente o aparentemente a una experiencia histórica: en ella se expresa la gesta de la evangelización hacia las gentes andinas y su conversión. Por ende, se la puede pensar en tanto un ícono de poder denso de significado que, desde la religión, estaría marcando la presencia gloriosa de la introducción de la doctrina católica en las vidas de los andinos.

¿Es posible abordar la recepción indígena de este proceso? El objetivo de esta reflexión es presentar y explorar fragmentos de cómo y dónde se representa el nuevo imaginario religioso. Para avanzar en esta problemática se discutirá la presencia de la cruz cristiana en el repertorio significante del arte rupestre andino colonial, desde la perspectiva de la apropiación selectiva del referente y de su utilización como signo de represión ${ }^{4}$. Para cumplir con este objetivo se utilizará una serie de materiales visuales

1 Facultad del Patrimonio Cultural y Educación, Universidad SEK. Fernando Manterola 0789, Providencia, Santiago de Chile, CHILE. Email: marenas131@gmail.com

2 Instituto de Historia, Pontificia Universidad Católica de Chile. Avenida Vicuña Mackenna 4860, Macul, Santiago de Chile, CHILE. Email: modoneco@uc.cl

3 Entendemos a los Andes del Sur como el espacio más o menos coincidente con el kollasuyu de los Inkas.

4 Para la problemática del sistema de arte rupestre en un contexto de producción colonial, véase Querejazu 1992 (ed.); Martínez 2009; Martínez y Arenas 2009; Arenas 2013. Por cautela metodológica es pertinente señalar que los materiales y datos aquí discutidos son producto del proyecto FONDECYT 1130431, complementados con otros materiales del proyecto FONDECYT 1090110, los que nos han permitido sistematizar fuentes etnohistóricas y etnográficas, amén del reconocimiento y registro de arte rupestre colonial en varios sitios del sur andino. Dichas observaciones fueron complementadas con fuentes secundarias sobre el mismo tema. En la presente discusión, hemos seleccionado 


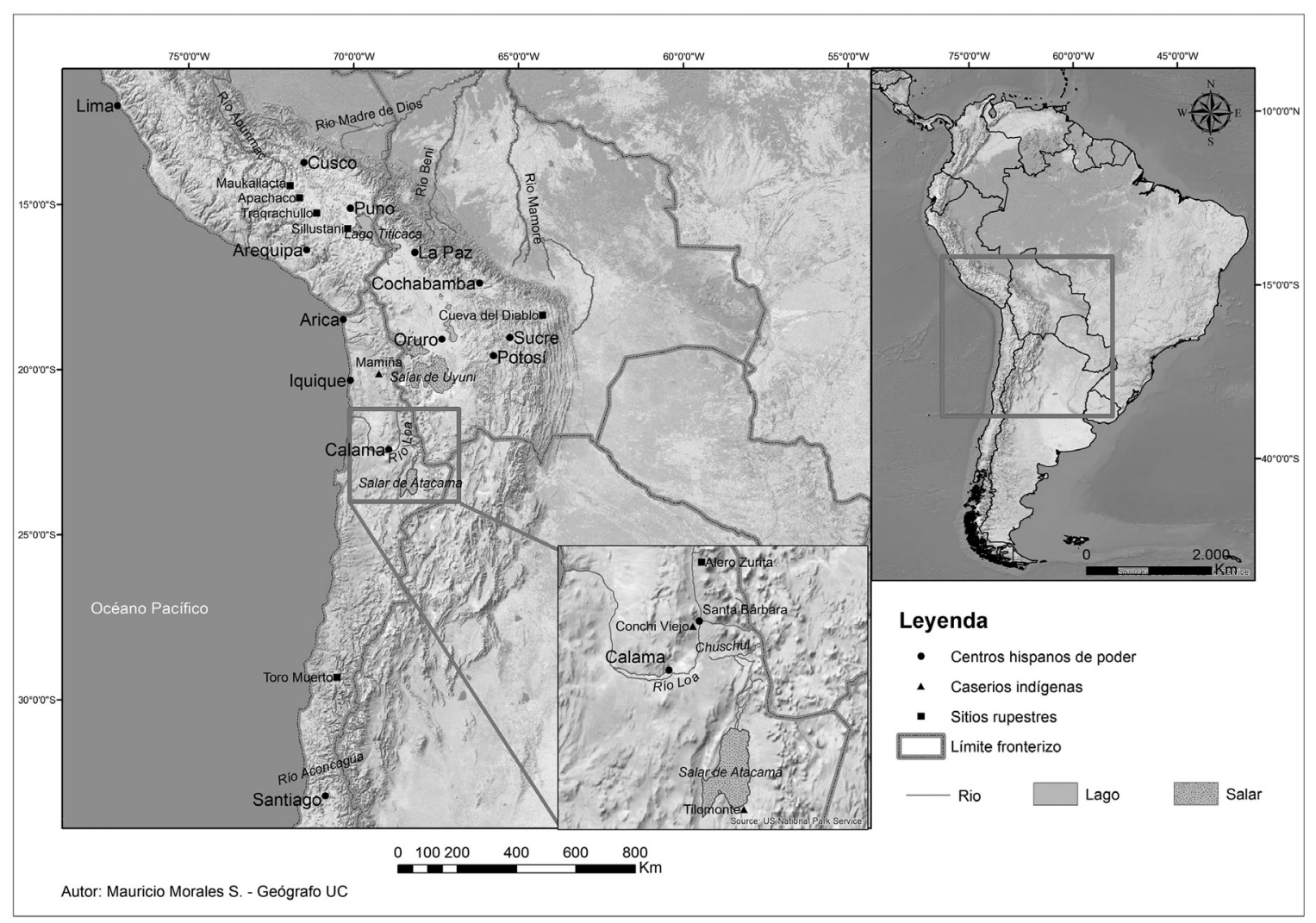

Figura 1. Mapa ubicación de los sitios mencionados en el texto.

relacionados con el sistema de representación visual rupestre, reportado en distintos espacios de los Andes del Sur y que, en su mayoría, se inscriben en el período de la colonización española de esos territorios (Figura 1).

un número acotado de sitios dispersos en un amplio territorio. Para un mayor detalle de los mismos, remitimos al lector a la bibliografía presentada. Una discusión preliminar sobre una cronología relativa en el sistema de arte rupestre colonial se encuentra en un trabajo en prensa desarrollado por Martínez y Arenas, presentado en el Coloquio Internacional de Arte Rupestre: La Vitalidad de las Voces Indígenas, realizado en la ciudad de Oaxaca, México, en abril de 2010.

5 En el sistema de arte rupestre distinguimos entre: cruz latina, como una construcción en donde el eje vertical es más largo que la cruceta horizontal y remite a la expresión más simple de una cruz cristiana; y cruz calvario, también conocida como cruz de atrio o cruz misional, es la que se presenta en forma recurrente como una cruz latina con base o pedestal, generalmente de forma escalonada. En el sistema de arte rupestre se representa con una variación en la configuración de su base, la que puede ir desde una simple línea o trazo perpendicular a la base, hasta formas complejas como bases circulares o radiadas (véase Arenas 2013).

\section{"Marcando" una presencia gloriosa}

La cruz católica ocupa un lugar relevante en espacios rurales de los Andes del Sur. Se la ve en la cumbre de colinas y montañas, levantada por pobladores para proteger sus lugares y pueblos, es la cruz grande o máxima, de madera o piedra, enterrada en la tierra o puesta sobre una base de piedra y barro. En caminos, laderas de cerros y en portezuelos o pasos de montañas, se distinguen cruces más pequeñas de piedra o madera, algunas pintadas, puestas en la tierra, sobre rocas, pequeños altares y al interior de capillas o ermitas. También están las situadas a la entrada y salida de los poblados, y fuera de sus iglesias, en los atrios o explanadas y portales, es la cruz calvario5 (Figura 2A). Estas son para los pobladores "seña y auki de su tierra nativa" (Arguedas 1989: 83-84). Igualmente se las ve al interior de los hogares; y en los techos de las casas, son las guardianas, pequeñas cruces de madera o latón, algunas veces desnudas; otras total o parcialmente cubiertas con lanas de color rojo, puestas para cuidar a sus moradores de seres dañinos, malditos o del mal agüero (Castro 


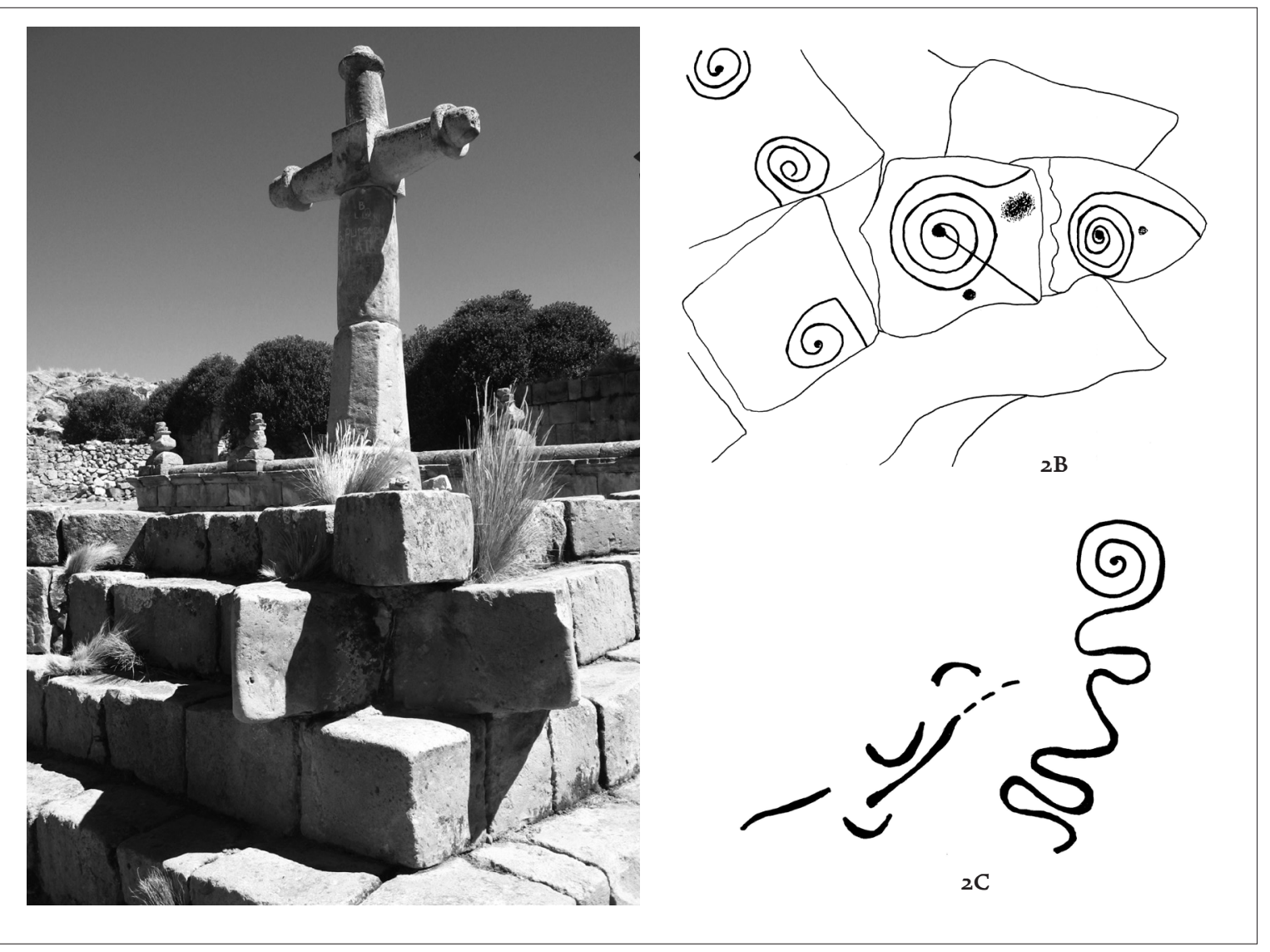

Figura 2: A) Cruz misional en el atrio de la iglesia del pueblo colonial de Apachaco, provincia Espinar, Perú. B) Detalle de la grada superior "estrellada" de la cruz misional de Apachaco con motivos grabados en espiral. C) Rasgos rupestres sobre la plataforma pétrea de la quebrada de Apachaco (Figuras $\mathbf{2} \mathbf{B}$ y $\mathbf{2} \mathbf{C}$ sin escala sobre la base de fotografías facilitadas por Rainer Hostnig).

2009: 400; Martínez y Arenas [en prensa]).

Para ceremonias, como las del agua y ganado, las cruces que están en los cerros, en algunos lugares, son bajadas por comuneros para pintarlas y ornamentarlas con flores, papeles de colores, o envolverlas con cintas, telas $y / o$ textiles; al igual que las que están en sus poblados. A estas se las adora, de variadas formas, compartiendo, bebiendo, bailando, comiendo, hablando y cantando (Arguedas 1998: 65-66). Para festividades religiosas católicas, como las fiestas patronales, las gentes también las componen, como bultos, pintándolas, vistiéndolas y adornándolas (Arguedas 1989: 87-90).

Un lugar especial ocupa el homenaje a la Cruz del Tres de Mayo, fecha en que el calendario católico conmemora el hallazgo de la Vera Cruz o "verdadera cruz de Cristo"
(Jiménez de Madariaga 2011). Y aunque la festividad es resultado del proceso de cristianización hispana, comuneros y devotos de los poblados participan de ella no sólo como respuesta a la imposición del calendario litúrgico católico. Para la víspera, el día de la fiesta y el de la despedida, además de los días de la octava, que se cuentan luego del tres de mayo, el día de la gran celebración, las cruces son enmarcadas con arcos florales o ramitas de árboles y cintas de colores; y junto con vestirlas se convierten en objetos rituales a los que se les ofrece incienso, velas, flores, bebidas, vino, chicha, licores, coca y alimentos; pidiéndoles permiso, ayudas y bendiciones ${ }^{6}$ (Ochoa 1976; Claros 1993; Gutiérrez 2013).

6 En el mundo hispánico, en poblados de Andalucía y Castilla, por ejemplo, para la celebración festiva de la Cruz del Tres de Mayo, calles, plazas, iglesias y el interior de las viviendas se llenan de 
En el Norte Grande de Chile, en los valles de Azapa y Lluta en Arica; en las quebradas tarapaqueñas, en localidades como Guaviña o Guatacondo; y en el interior del río Loa, en poblados como Ayquina y Toconce, la fiesta comprende, entre otras celebraciones, la bajada de la cruz desde lo alto, generalmente un cerro, siendo vestidas y adornadas; luego el velorio, donde son acompañadas con cantos y oraciones; y finalmente la subida o festividad de la partida, ofrecida por grupos de bailes, bandas de bronces o tropas de zampoñas y/o lakitas, para luego compartir comidas y bebidas preparadas para la ocasión (Barrientos 1984: 120; Castro 2009: 450). En poblados del sur de Perú, como los situados en el valle de Vilcanota, y en el valle de Cochabamba (sur de Bolivia), se la celebra para la víspera, la fiesta y despedida con bandas de flautas, bombos, tarkas, sicuris y pinkullos junto a comparsas de bailes, fuegos artificiales y cohetes que revientan. Puede haber misas, rezos de rosarios y peregrinaciones; y en algunos casos, las cruces adornadas recorren, en romería, las calles de las localidades portadas

cruces adornadas con flores, joyas, mantos, telas bordadas, encajes, terciopelos, entre otros. Son puestas sobre altares decorados, con y sin arcos, poniendo a sus pies adornos variados. Pueden participar o no cofradías, celebrarse misas, rezos del rosario y romerías; al igual que bailes y cantos; bendiciones de los campos; convites de comidas, dulces y bebidas; fogatas, desfiles de reinas y carros alegóricos, luchas de toros, cohetes y fuegos artificiales, entre otras actividades. Celebración festiva no sólo con raíces en formas religiosas paleocristianas, sino que hundiéndose más allá, en el culto a los árboles, a divinidades asociadas con la naturaleza y su abundancia; a festejos de las cosechas, de la primavera y del amor (Jiménez de Madariaga 2011).

7 Si bien el presente trabajo no intenta dar cuenta de la fiesta de cruces en el ámbito de los Andes, sí nos parecen muy interesantes las investigaciones de carácter antropológico y etnohistórico que profundizan la comprensión de la fiesta de cruces y su celebración en los Andes Centro Sur. Se aprecia que la fiesta tiene un lugar central en la cartografía espacial y ritual de muchos poblados, protegiendo viviendas, tierras, caminos, cerros, animales, cosechas; reconociéndose que las gentes andinas participan activamente de una fiesta impuesta por la Iglesia Católica, impregnándola de su propia y distintiva atmósfera cultural. Observándose que allí hay una concurrencia de tradiciones y costumbres antiguas, como las asociadas a los ritos agrícolas y solares, o a celebraciones coloniales como el Corpus Christi, las que se actualizan y ponen en movimiento en cada nueva celebración (Van Kessel 1996; Molinié 1999; Zuidema 1999). por cargadores, haciendo paradas en altares dispuestos en distintos sectores (Arguedas 1989: 84; Claros 1993).

Y si a las cruces se les ofrecen inciensos y prenden velas, rezándoles para agradecer y obtener abundancias, bendiciones y felicidad, se corresponde que se las trate con cariño y mucha cercanía; hablándole a Taytacha, a Tata Velacrus, a Velacrus, a Tatito Santa Cruz, a Tatita, Tatay, Tatala, y Tata Espíritu. Expresándoles deseos de obtener buenas cosechas, multiplicación del ganado, bienestar y salud para la familia y la comunidad (Irarrázaval 1980a, 1980b; Equipo Pastoral de Lampa 1980).

La presencia de la cruz en los Andes rurales del sur remite a la experiencia histórica de conversión de las gentes andinas, marcando la presencia triunfante de la introducción de la doctrina católica en sus vidas? ${ }^{7}$. Siendo entonces la figura de la cruz un ícono, una marca, dado que su dimensión visual y su despliegue sensorial exhibe y se conecta, por semejanza o similitud, con los discursos de la evangelización católica. A la vez es un ícono de poder denso de significado, dado que contiene la fuerza de una síntesis: la acción hispana de que los andinos adoptaran formas de la cristiandad. Ciertamente, esta es una de las cualidades interesantes de la dimensión material de las cruces, sin embargo "todo lo que significa, significa algo para un interpretante" (Bitonte 2012: 15-19). Esto, entonces, lleva a reconocer que las cruces, en tanto íconos, sólo estarían mostrando una parte de muchísimas otras caras.

A su vez, si las cruces, en tanto soportes materiales, forman parte de condiciones de producción y reconocimientos o aceptaciones/recepciones insertas en la vida social de los grupos humanos, lo que no está exento de consensos y conflictos (Verón 1988: 124-127), cabe preguntarse: ¿es posible abordar, en los Andes del Sur rurales, la recepción indígena del proceso de incorporación de este ícono?

\section{Las fuentes de lo imaginario: significante y signifi- cado para integrar a las indianidades}

El proceso de cristianización temprano de los Andes del Sur está asociado con estandartes de imágenes de santos, vírgenes y cruces que acompañan a ejércitos en sus labores de conquista de territorios y gentes, como las cruces de palo atravesando paisajes, protagonizando milagros 
de conquista y luchas contra los diablos, permitiendo su presencia derribar a deidades antiguas ${ }^{8}$ (Estenssoro 2003: 445-446):

"El soldado con esto hizo una grande Cruz, y pusola en alto, y mándoles que adorasen alli, y pidiessen agua y ellos lo hizieron assi: Cosa marauillosa. Cargó luego tan copiosissima lluvia, que los Indios cobraron tanta deoucion a la Sancta Cruz, que acudian a ella con todas sus necesidades. Tanto que vinieron a derribar sus ydolos, y a traer la Cruz por insignia”.

La cruz se despliega, material y sensorialmente, para reconocer a indígenas que son aliados de españoles, creando sentidos de protección material; constituyéndose su presencia en un acto de negociación política que no sólo se moviliza, en tanto fuerza simbólica, para destruir significados anteriores, sino que se constituye en un emblema de defensa contra los indígenas enemigos que resisten la invasión y, por consecuencia, la nueva religión:

"Pues estando en esta confusión cucedio que un yndio de este Túmbez uino de paz, el qual dixo al Marqués que él no auía querido yr porque sauía qué cosa era guerra, y que auía estado en el Cuzco, y que le parecía que los españoles eran hombres de guerra y podían mucho, y que lo auían de conquistar todo, y por esta causa no se auía querido huir con los demás, y que mandase que no le rrobasen su casa. El Marqués le dixo que hiziese poner una cruz donde uiuía, y que él mandaría que no tocasen allí, y así mandó a un Rodrigo Núñez (que herarrepartidor de las comidas y echaua las uelas), que mandase echar un pregón que en la casa donde uiesen una cruz no llegasen a ella"10.

Diversos estudios han puesto especial hincapié en las instrucciones que el Arzobispo de Lima Jerónimo de Loayza dio en $1545^{11}$ sobre el modo de llevar a cabo la evangelización de indígenas, donde el despliegue material de cruces tenía un lugar central, particularmente en los lugares donde ellos tenían sus wak'as y adoratorios:

"[...] en los adoratorios de los caminos que los yndios llaman apachetas, procuren los sacerdotes cada uno en su distrito quitarlos y deshacerlos del todo, y en eso se les pone precepto y si les pareciere cosa decente, pongan una cruz en su lugar" ${ }^{\prime 2}$.

Manifestaciones importantes de la cristianización del paisaje fueron las disposiciones del primer Concilio Provincial Limense (1551-1552) sobre la construcción de iglesias y capillas:

"en el pueblo donde residiere el cacique principal, se haga una casa a manera de iglesia donde los indios se junten a oír la doctrina cristiana y donde se diga misa, adornando el altar de la mejor manera posible y poniendo en él alguna imagen o imágenes" ${ }^{\prime \prime}$.

Centrales fueron también las disposiciones, como las indicadas en el Sínodo Quitense de 1570, que señalaban que se pusiesen cruces en todas las entradas de los pueblos, junto a las iglesias, ordenándose además "poner cruces a los caciques y señores en sus patios para que allí juntasen sus yndios a rrezar ${ }^{114}$. O las que decretaban que, antes de entregarse los sacramentos, los indígenas tenían que saber santiguarse, además de las oraciones del Credo, Padre Nuestro y Ave María, entre otras enseñanzas de la fe, disposiciones que se reforzarían en el segundo y tercer Concilio Provincial Limense (1567-1568 y 1582 1583 , respectivamente) $)^{15}$.

Por otra parte, el santiguarse, en tanto lenguaje gestual, estaba asociado a contextos del buen vivir, limpieza y modales adecuados:

“[...] digan la bendición á la mesa y den gracias después de comer, y quando van á dormir se encomienden a Dios, y á menudo se persignen, y santiguen, y digan el Credo, y el Pater noster, y el Ave Maria: en lo qual principalmente sean instruidos los Caziques y Mayorales, para que los demás tomen egemplo [... $]^{p 6}$.

Esta pedagogía, junto a la de las oraciones, era central en la catequesis de los indígenas, la que debía efectuarse, desde el segundo Concilio Limense, a lo menos tres

8 También resultan interesantes los trabajos efectuados respecto de la cruz en contextos de Chile meridional. Véase Valenzuela 2012.

9 Acosta 1590: 526.

10 Pizarro 1978 [1571]: 22-23.

11 Estenssoro señala que se conserva una versión revisada de la Instrucción que se ha de tener en la Doctrina de los naturales de 1549 (2003: 33).

12 Vargas, S.J. 1951 (I): 253.

13 Vargas, S.J. 1952 (II): 139.

14 Vargas, S.J. 1952 (II): 168.

15 Vargas, S.J. 1951 (I): 230, 244, 323-324; Armas 1953: 250-251.

16 Peña Montenegro, de la. 1771. Lib. I. Trat. I. Secc. X: 70. 
veces a la semana y los días de fiesta, a fin de que los indígenas aprendiesen las oraciones, supieran santiguarse, teniéndolo todo en la memoria, cuando se levantaban y acostaban ${ }^{17}$.

Durante el gobierno del virrey Francisco de Toledo (1569-1581), el gran reformador del Virreinato del Perú, los Andes del Sur serán un espacio fuertemente controlado, reagrupándose a las poblaciones indígenas, sus territorios y autoridades locales de acuerdo al modelo de reducciones; medida que tendría como correlato hacer más eficiente la cristianización de los indígenas a través de la conformación de pueblos, parroquias y doctrinas de indios, siendo central que los corregidores vigilasen las conductas de los doctrineros ${ }^{18}$. Toledo tomará medidas administrativas en torno a la depuración de formas indígenas, observándose que las cruces serán integradas a "la política de control sobre la elaboración de imágenes no cristianas, y a la mantención bajo vigilancia de la labor misma de algunos de los artesanos que las elaboraban" (Martínez 2012: 188). Ya no sólo ellas se inscribirían en el ámbito de la política de evangelización, sino que también se convertirían en índices de exclusión visibles, o borradores de memoria, de todo lo que recordara tiempos indígenas pasados:

"Y las pinturas y figuras que tuvieren en sus casas y edificios y en los demás instrumentos que buenamente y sin mucho daño se pudieren quitar y señalareis que se pongan cruces y otras insignias de xptianos en sus casas y edificios"

Las instrucciones pastorales que surgieron luego del tercer Concilio Provincial Limense (1582-1583), siguieron esa misma línea, es decir, "la normalización radical y una toma de distancia respecto del pasado indígena" (Estenssoro 2003: 298). Extendiéndose a sermones, indicaciones sobre la celebración de fiestas religiosas y

17 Armas 1953: 277; Peña Montenegro, de la. 1771. Lib. I. Trat. I. Secc. IX: 69 .

18 Armas 1953: 479-486.

19 Toledo 1924 [1570-1575]: 171, citado por Martínez 2012: 188.

20 Ricardo 1585, citado por Valenzuela 2006: 495.

21 Vargas S.J. 1951 (I): 8. Las ausencias de información sobre la materialidad de las cruces se hace extensiva a campanas, sagrarios, cementerios y pilas bautismales de las iglesias menores y capillas (Peña Montenegro, de la. 1771. Lib. I. Trat. I. Secc. I: 3). devoción a imágenes de Cristo, santos y la Virgen María, conformándose también modos de acercarse a las imágenes, y por extensión a la cruces, desde el presupuesto que ellas "cultivaban las conciencias" (Estenssoro 2003: 250; Valenzuela 2006: 41-66). Las imágenes no sólo tenían una función pedagógica, sino que también el rememorar y evocar, trayendo al presente de la vida de las gentes andinas, los significados que ellas portaban, todo ello enmarcado en acciones performativas compuestas por gestos visuales, orales y sensoriales: "yd a las iglesias por las mañanas, y allí hazed oracion cada dia, sin faltar ninguno y también a las tardes, tomando agua bendita y besando la cruz, y mirando las imágenes"20.

Uno de los resultados importantes del tercer Concilio Provincial Limense fue la elaboración de tres textos fundamentales: una doctrina cristiana, dos catecismos (uno mayor y otro menor) y un primer manual de confesión, los que fueron impresos en 1585 tanto en versión castellana como en las dos lenguas generales, aymara y quechua. En ese ámbito de aplicación, llama la atención que la escritura fue uno de los vehículos principales para transmitir la importancia de la cruz católica entre los indígenas que eran evangelizados, lo que permite sugerir que la cruz se configura, en tanto imagen, desde el contexto de la palabra, y desde sus aspectos materiales y sensibles.

Hasta el momento de la presente investigación, no se cuentan con indicaciones que refieran o aludan a tipos de cruces, modos de construirlas, preferencias en el uso de materiales para su elaboración, o bien, qué tipos de cruces se ponen en las iglesias, capillas, altares y otros lugares (Durán 1982). Aunque ya en 1552 se indicaba que la ornamentación de las iglesias debía estar en directa relación con "la dignidad del lugar"; y si no había posibilidades de construir una iglesia o capilla, debían edificarse casas pequeñas a modo de ermitas. Y si esto no era posible se establecía que "[...] a lo menos señalen un lugar decente con una cruz, donde se les diga la doctrina y platique las cosas de la féé"21.

Es solo desde el contexto de la palabra que se levanta una imagen de la cruz asociada al Evangelio, a la identidad de la persona de Jesucristo y al poder contra el demonio y el pecado, siendo además exaltada en los pasajes de mayor dramatismo del dolor, muerte y resurrección de Jesucristo. La imagen de la cruz, en tanto palabra, seguía ligada 
a las enseñanzas de la doctrina católica, y a las oraciones esenciales que debían practicar las gentes indígenas, quienes debían acompañar las recitaciones del Ave María, la Santísima Trinidad y el Padre Nuestro con el gesto del signo de la cruz (Valenzuela 2007: 43-44).

\section{La extirpación de la idolatría}

A comienzos del siglo XVII, en el contexto de procesos de extirpación de idolatrías y represión a las wak'as, se informa de ciertas características materiales de la cruz, señalándose que un momento muy importante de la finalización de las visitas o revisitas a los pueblos de indios era la instalación de una cruz grande en la plaza, estableciéndose simultáneamente la celebración de:

"[...] el día de la exaltación de la Cruz, el 14 de setiembre o el domingo siguiente, en memoria de la merced que les hizo Nuestro Señor de sacalles de sus errores e idolatrías. Y por la misma razón se pone para este día, y queda muy bien puesta para adelante, una cruz grande en la plaza"2.

Más allá de los combates que se inician entre la cruz y los símbolos locales, y la permanente queja de los evangelizadores sobre que la tarea de la catequesis parece no avanzar y que la evangelización no es una batalla ganada, llama la atención la característica formal de la cruz grande, situada en un espacio muy visible, funcionando como monumento que conmemora el cumplimiento de la limpieza de formas religiosas andinas contrarias a la fe católica; y por ende sería un marcador visible de la memoria sobre el presente - la extirpación idolátrica-, destruyendo el pasado. Ello permite sugerir que, en ese contexto, funcionaría como monumento de conmemoración de higienización cultural, celebrándose que allí sucedió la represión, que la destrucción de la supervivencia pública o clandestina de prácticas absolutamente contrarias a la fe católica y sus enseñanzas ocurrió allí, en un espacio totalmente lleno de cosmovisión andina: "apeose el Padre cogiendo la Cruz, que llevavan para poner donde estaba la Huaca"23.

22 Arriaga 1621: 100. Información que resulta interesante puesto que permite pensar en una suerte de relación entre el asentamiento de la cruz en las plazas de las iglesias y su posible vinculación con visitaciones de religiosos.

23 Arriaga 1621: 120.
Este proceso de instalación de cruces también se extiende al soporte del arte rupestre, siendo posible pensar que fueran productores hispanos especialistas, ya sean sacerdotes, jueces visitadores y/o acólitos, los encargados de marcar el espacio rupestre y otros "signos de la idolatría", con sendas cruces grabadas o pintadas con el fin de extirpar la idolatría. Es el llamado arte rupestre iconoclasta que marcó al sistema de arte rupestre en espacios de circulación del poder colonial español, asentándose sobre vías de circulación densamente significadas por comunidades nativas. Lo que se detecta en sitios de arte rupestre prehispánicos ubicados a la vera o cercanos a caminos que conectaban los principales enclaves de producción y comercialización mercantil hispana, por ende, siempre a la vista de los españoles. Luego, se estaría ante una construcción iconoclasta, que sirve a los intereses de la evangelización desde la implementación del poder colonial europeo en los Andes (Bednarik 1992).

Ejemplos de ello se observan en los sitios de Peña Escrita, cerca de Chuquisaca o Sucre en Bolivia (Bednarik 1992), en la Puerta del Diablo, quebrada de San Bartolomé, en las cercanías de Potosí (Absi y Cruz 2006), o las que se advierten en los farellones de Santa Bárbara, un importante cruce de caminos en el Alto Loa (Figura $3 \mathrm{~A}$ ), comunicando las tierras altas con la costa del Pacífico, en la actual II Región de Antofagasta (Chile). En todos estos sitios se inscribieron, sobre motivos grabados o pintados - evidentemente en tiempos prehispánicos-, cruces cristianas latinas $y / o$ de atrio o calvario con pedestal, con el claro objetivo de anular el poder simbólico de las representaciones indígenas y proclamar el poder del Evangelio sobre las wak'as. Esos espacios fueron marcados por la represión iconoclasta no sólo por el hecho de haber sido construidos en el tiempo de la gentilidad, sino y fundamentalmente porque esos espacios habrían continuado funcionando en una dimensión sacra y sobrenatural en el período colonial, al momento de la llegada de la represión anti idolátrica. En consecuencia entonces, en contextos asociados a procesos históricos de represión, las cruces, preferentemente de atrio o calvario con pedestal, funcionaron en la marcación de la llamada idolatría en los espacios de circulación del poder colonial, incluyendo al arte rupestre cercano a esos caminos.

Otro ejemplo de ello es la cruz tallada en la corteza de un tamarugo situado en Tilomonte, al sur de la localidad 


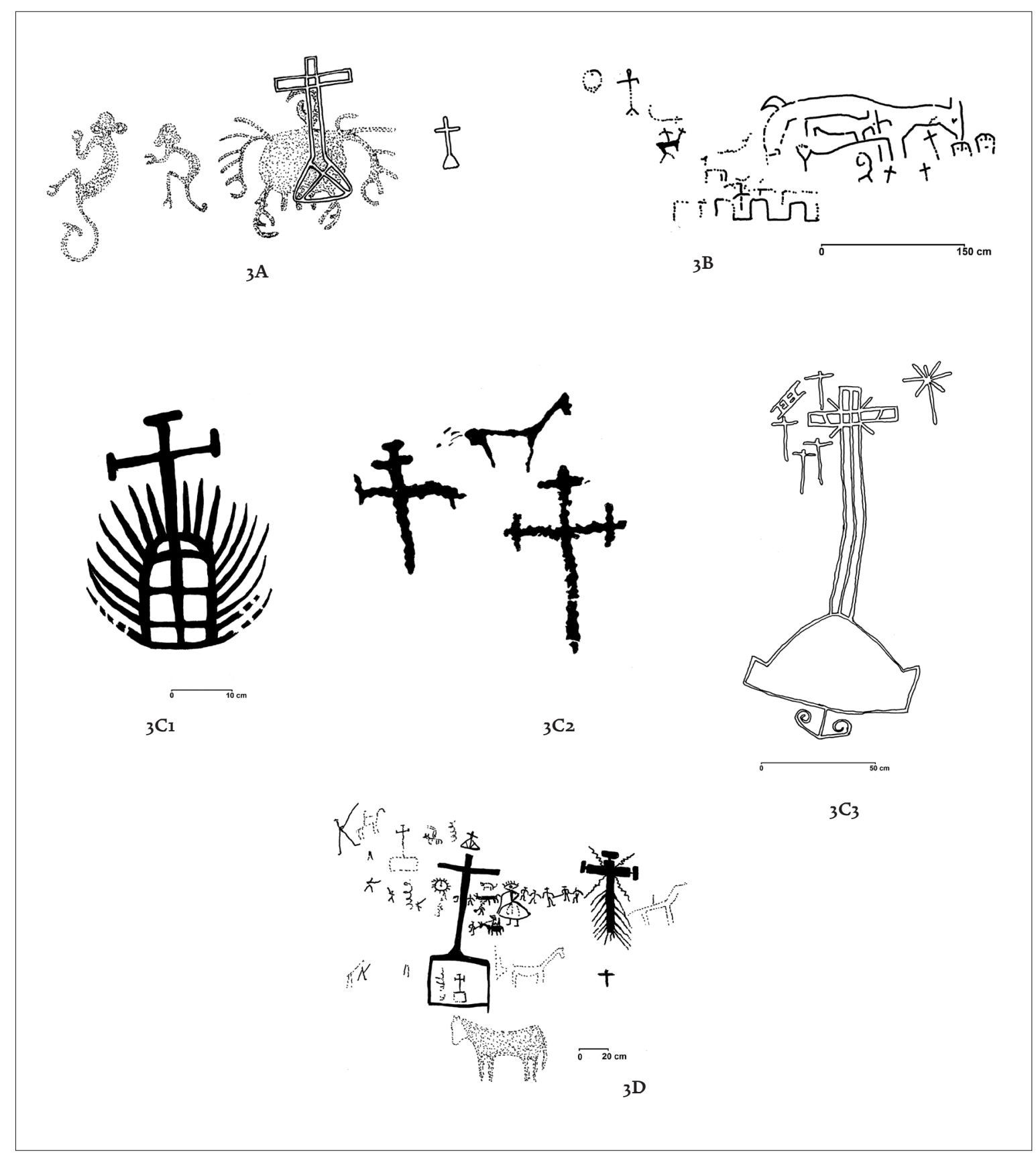

Figura 3: A) Cruces de calvario o de atrio grabadas sobre otros motivos grabados de estilo prehispánico en un panel frente al cruce de Santa Bárbara, Antofagasta, Chile (la cruz mayor sobrepasa $1 \mathrm{~m}$ de altura). B) Cruces latinas integradas a un panel de grabados de estilo prehispánico en el sitio de Chuschul, Antofagasta, Chile (detalle panel 1 grupo i según Niemeyer, 1967: 86). C) C1: Cruz pintada en color rojo en el sitio de Manqalaca, Suero, Perú. C2: Cruces potenzadas y camélido grabados en el sitio de Tola Palca, Oruro, Bolivia (la cruz mayor no sobrepasa los $25 \mathrm{~cm}$ de altura, según Querejazu, 1992: 17). C3) Cruz calvario o de atrio grabada en un bloque pétreo del sitio Toro Muerto, Coquimbo, Chile. D) Conjunto significante colonial en el sitio de Calera, provincia Espinar, Perú ( ${ }_{3} \mathbf{C l}_{1}$ y $3{ }_{3} \mathbf{D}$ sobre la base de fotografías facilitadas por Rainer Hostig). 
de Peine (salar de Atacama, II Región de Antofagasta, Chile), con la rúbrica año 1681 (Hidalgo 2012). En este soporte, la cruz de atrio o calvario con pedestal contiene tres atributos distinguibles: tamaño, forma lisa y saliendo de una estructura de base piramidal. En este caso la cruz también estaría asociada a un contexto de producción de apropiación simbólica del espacio que, en tanto hito demarcatorio, funcionaría en una doble dirección: de un lado están los territorios que forman parte de la órbita cristiana; y de otro lado, están los territorios que quedan fuera de ella; más allá de Tilomonte estaba el inicio del camino del gran despoblado de Atacama, espacio que se extendía entre el sur del salar de Atacama y el río Copiapó (actual norte de Chile), significando para los hispanos un espacio inhóspito, árido, vacío, improductivo e inhabitable (Sanhueza 2005: 51-52). El ícono funcionaría como parte de una estrategia hispana de control y apropiación simbólica del espacio, ya que instalar cruces en los territorios indígenas significaba que ellos ingresaban a la órbita de la cristiandad. Aquellos eran, desde entonces, territorios y gentes bautizadas, conformando parte de una cartografía donde cada una de las cruces actuaba como nudo de una malla mayor de evangelización (Hernández 2006: 29).

\section{Cruz en las piedras: otros protagonistas, otros creadores}

En el contexto de la recepción indígena, para el período colonial temprano el proceso del Taqui Ongoy entrega luces importantes para comprender procesos de apropiación selectiva del significante. Es en ese tiempo de resurrección de las wak'as para luchar contra el dios todopoderoso de los cristianos, donde sacerdotes y apóstatas de la fe toman nombres de santas y santos cristianos y reconocen el poder del dios católico, pero al mismo tiempo, niegan el poder de la cruz de palo. En este mismo proceso, como parte de la represión a los apóstatas y hechiceros, se les impone como castigo llevar una manta, ya sea pintada o bordada, con una cruz invertida (Varon 1990; Millones 2007).

La forma de la llamada cruz de palo, en los años subsiguientes, se posicionará como uno de los referentes icónicos del cristianismo a nivel popular. A pesar de su negación en el Taqui Ongoy, cuestión que también puede ser parcial, se observa la asimilación del cristianismo en el contexto de la cultura propia, puesto que estos sacerdotes bautizan y mochan en nombre de las wak'as y hacen misa con chicha. En estos testimonios es posible apreciar una de las dimensiones de la recepción indígena del Evangelio, lo que aquí se reconoce como un índice del proceso de apropiación selectiva. Evidentemente se está en presencia de una asimilación parcial del cristianismo, esa que integra para sí parte del poder reconocido en el dios de los cristianos y que refuerza, posiblemente, la eficacia simbólica de los ritos en el contexto de la cultura propia. De ahí su carácter de apropiación selectiva.

Ahora bien, ¿qué está ocurriendo en ámbitos de la ruralidad, en espacios más alejados de los centros de poder urbano y/o mercantil, lejos de la circulación oficial y vigilante del poder colonial español? ¿Se distinguen allí cruces latinas y de atrio o calvario con pedestal? ¿Se aprecian en ellas formas y prácticas que estarían remitiendo a otras soluciones de construcción?

Observando un panel pintado del alero Zurita, en el alto Loa, se distingue una cruz de atrio o calvario pintada y de base piramidal triangular, la que está dispuesta sobre un conjunto representacional de indudable factura prehispánica. Entre ellos, y en una situación levemente inferior, se observa, entre otros motivos, un cóndor pintado en rojo, propio de los estilos de Tarapacá, y más abajo una recua de camélidos, lo que permite dar cuenta de que el sitio está asociado a una estación de caravaneros (Berenguer, 1999). Lo interesante es la disposición de la cruz de atrio o calvario, de atributos similares a las cruces iconoclastas, que se encuentran funcionando en los paneles rocosos frente a la posta de Santa Bárbara, o grabadas en forma aislada en las paredes de la cercana quebrada de Quinchamale, por donde avanzaba un camino que comunicaba la caja del río Loa con el vecino pueblo minero colonial de Conchi Viejo (II Región de Antofagasta, Chile). En definitiva, la misma cruz calvario que por disposición y construcción formal se talló hacia fines del siglo XVII a la salida del pueblo de Tilomonte para marcar el inicio del gran despoblado.

Una situación contraria es la que se observa en otro sector del panel. Lo que llama la atención de la disposición de la cruz de atrio o calvario en el conjunto representacional, es que esta no interviene los motivos preexistentes. Por el contrario, se integra o cohesiona, en posición 
o planteamiento de continuidad, con los otros motivos, observación que se asocia con la noción de solidaridad diacrónica ${ }^{24}$. Esta forma de funcionar, en solidaridad o cohesión diacrónica, se detecta en otros sitios del espacio andino, ya sea en técnica de pintura o grabado, o incluso integrándose a la monumentalidad de la representación de los llamados geoglifos (Chacama et al. 1988-89; Chacama et al. 1992). Es el caso, por ejemplo, del sitio Tambillo-2 (Moraga 1996), un alero cercano a la localidad de Mamiña (Región de Tarapacá, Chile), o las cruces latinas que percolan uno de los paneles del sitio de Chuschul o Salado, afluente del río San Pedro en la cuenca del gran salar de Atacama (Niemeyer 1968) (Figura 3B). Es una forma recurrente de remarcar espacios o antiguos sitios con significantes rupestres prehispánicos, con nuevos significantes coloniales de acentuado contenido cristiano, integrándose en términos armoniosos, solidarios con el conjunto significante ya existente, pasando a reforzar contenidos simbólicos de un espacio sacralizado al menos desde el tiempo de la gentilidad, y que en el contexto colonial siguen funcionando con su carga sobrenatural.

Se observa entonces una copresentación, donde lo hispano religioso es un elemento más del cuadro mayor de símbolos de tradición prehispánica. Entonces, iesta forma de representación estaría indicando que sus condiciones de producción no responden a un programa iconográfico doctrinal y devocional impuesto por evangelizadores? ¿Ello habla de contextos de producción de apropiación selectiva del significante por parte de productores andino coloniales? Se considera que sí.

Pero la apropiación selectiva no se reduce a una solidaridad diacrónica con conjuntos representacionales prehispánicos, ya que primero tiene que ver con una opción selectiva del significante. En este punto, vale la pena recordar que esta opción afecta también a otros significantes, y que un número acotado de motivos son los que se integran al repertorio del sistema rupestre andino colo-

24 Mege y Gallardo Ms. en poder de los autores. Rescatamos la noción en torno a los paradigmas representacionales como asociaciones de significantes solidarios en sincronía (Mege 2000). En este sentido, la propuesta de solidaridad diacrónica operaría como una asociación de significantes en relaciones solidarias pero pertenecientes a paradigmas visuales de diferentes momentos históricos. Funcionaría en un sentido relacional opuesto a la “inscripción” iconoclasta (sensu Bednarik 1992). nial (Martínez y Arenas 2009). Aquellos de mayor valor diagnóstico lo constituyen los significantes figurativos entre los que se cuentan, además de las cruces cristianas como las más extensas y densamente representadas, motivos tales como iglesias católicas, sombreros, procesiones, conflictos bélicos y antropomorfos que remiten a sacerdotes cristianos. Un lugar particular ocupa el motivo ecuestre, observado al menos, desde tres dimensiones. Por una parte, en su asociación con la apropiación de San Santiago Illapa (Gallardo et al. 1990); por otro, en tanto indicador temprano de construcción de alteridad colonial (Martínez y Arenas 2009; Arenas et al. 2015); y por último, como indicador más tardío de contextos de conflictos armados (Strecker y Taboada 2004).

Lo cierto es que en esta dimensión figurativa se apela, en la representación rupestre, a un conjunto acotado de significantes, especialmente religiosos cristianos, y que es muy difícil, si no imposible, asimilar al plan doctrinario evangelizador expresado en el despliegue visual de los muros de iglesias y capillas cabeceras de repartimientos y curatos. Las coincidencias entre ambos sistemas son mínimas y sólo estarían dando cuenta de una excepción a la norma, lo que permite pensar que las apropiaciones y usos selectivos de significantes apelarían a elecciones por calidad y no por cantidad: un número acotado de significantes son absorbidos dentro de un propio lenguaje o integrados a lo propio, haciendo más fuerte el sentido de identidad, permitiendo a la vez que los significantes que han sido y los significantes que son, como las cruces, se relacionen en continuidad, constituyéndose un campo representacional que remite a la idea de reunión, pero también a un escenario, a un fondo de valores representativos, "aquello que permite que los que han sido y los que serán se relacionen con nosotros, los que somos en ese foro que llamamos sociedad" (Pérez 1998: 81).

Volviendo a la cruz latina y de atrio o calvario y todas las variantes de las mismas que se despliegan profusamente tanto en antiguos sitios de arte rupestre, y también en otros de construcción colonial, en contextos de apropiación del cristianismo, se observa claramente que el hacedor y/o productor efectúa elecciones culturales específicas, lo que remite a que se sitúa en tanto un interpretador, tal como sugiere Eliseo Verón (1988), recortando y seleccionando fragmentos de discursos para rearmarlos, lo que también habla de la existencia de determinadas 
condiciones de reconocimiento y/o aceptación de los significantes.

Se puede afirmar que la presencia de la cruz latina es significativa en distintos repertorios del arte rupestre andino. Se la puede observar, ya sea en técnica de grabado, pintura o geoglifo, en aquellos espacios que desarrollaron, independiente de los estilos locales, una rica tradición en la ejecución de obras de arte rupestre. En muchos de esos sitios funcionaron por solidaridad diacrónica, pero muchos otros se construyeron en el contexto colonial, posicionando a la cruz latina en su repertorio, como un significante exclusivo de dominio visual (Hostnig 2004; Arenas 2011) (Figuras $3 \mathrm{Cl}_{1}, \mathrm{C}_{2}$ y $3 \mathrm{C}_{3}$ ).

\section{Movimiento inverso: de las piedras de los cerros a las cruces de plazas y atrios}

En contextos espaciales de poblados coloniales rurales se reconocen otras caras del proceso de apropiación selectiva, observándose soluciones representacionales que describen un movimiento inverso: ya no son las cruces las figuras protagónicas, sino que ciertos motivos rupestres precoloniales que se incorporan a las cruces. En efecto, en el departamento del Cusco, las cruces de las plazas de la mayoría - sino de todos- los pueblos coloniales del departamento presentan en las gradas de su base, generalmente de forma piramidal escalonada, litograbados, motivos conseguidos por percusión directa y raspado, consistentes en líneas sinuosas, junto a motivos abstractos, espirales y cúpulas, éstas últimas muchas veces conectadas por líneas en forma de canales. Por las huellas de uso, se infiere que estas imágenes se combinan con rituales de quema y posible libación y derrame de líquidos, en algunos casos aún en la actualidad (del Solar y Hostnig 2004) (Figura 2B).

Muchos de estos motivos forman parte de repertorios iconográficos prehispánicos existentes en las alturas de los cerros, cerca o en importantes poblados que continuaron funcionando durante el período colonial temprano en los Andes del Sur. Ello se observa en el pueblo colonial temprano de Apachaco Huayco, en las tierras altas al sur de Cuzco (actual provincia Espinar, Figura $2 \mathrm{C}$ ), como en Traqrachullo y Maukallacta, en territorio cana. El primero, también conocido como María Fortaleza, presenta un complejo sistema de cúpulas y canales situa- do en una pequeña meseta colindante al poblado, en la cima de un cerro. También se observan, en las peñas que flanquean la escalera que comunica el sector bajo con el sector alto del poblado, muchos surcos dispuestos como líneas sinuosas, figurando pequeños canales que bajan de las piedras. Lo mismo se reconoce en Maukallacta, en una peña en el centro del poblado, y en el piso de rocas en lo alto del farallón que le sirve de contrafuerte, desde donde se domina el poblado y parte del curso superior del río Apurimac. Allí están grabadas cúpulas, un espiral y líneas sinuosas, una de ellas con apéndice, figurando la cabeza de un ofidio. Por su parte, y en territorio del antiguo señorío colla, igualmente se observa un repertorio iconográfico similar, así en la monumental necrópolis de Sillustani (laguna de Umayo, Puno, Perú), una de las chullpas presenta marcas litograbadas en rocas dispuestas en su base.

Resulta sintomático reconocer, por una parte, que la tipología representacional cúpulas, espirales, líneas sinuosas y/o canales se presente en distintos sitios de arte rupestre prehispánico. Por otra parte, esta tipología de litograbados está migrando desde cerros y quebradas, instalándose en la base de cruces de atrio o calvario, lo que diagnostica la posible relación dialógica entre su disposición y ritos relacionados con el agua y fertilidad que esta brinda a la tierra. En estos contextos, la cruz de atrio o calvario no funciona como una marca iconoclasta, si no como una marcación de un espacio cristianizado. El movimiento de "motivos rupestres", que bajan de los cerros y quebradas a las bases de las cruces de atrio o calvario, parece estar guiado por otras preocupaciones. Cabe la pregunta: isi se cambia algo de lugar, en este caso, los litomorfos, se pierde algún sentido? O bien, ¿el movimiento de estos significantes indígenas otorga "otro" sentido a aquello que está en el lugar? Se considera que con el desplazamiento de significantes se está ante otras producciones de sentido, construidas a partir del mecanismo de apropiación selectiva que permite la actualización de memorias, creencias y formas de comprender el mundo al margen del control hispano. Allí no hay readecuaciones ni asimilaciones, sino que pervivencias de una tipología de profundidad prehispánica en el contexto de un soporte tan denso de significado como el ícono de la cruz.

José María Arguedas escribía en 1941 que "en el tejado de las casas, varias cruces de hojalata o acero, alternadas con 
toros de barro, protegen a las casas" (1989: 83-84). ¿Sería dable pensar que, etnográficamente, estaríamos ante un movimiento donde hay una "apropiación" para expresar identidades en las posiciones de las cruces en las casas?, io conjugadas de otras maneras, con toros, por ejemplo, en las techumbres? Movimientos similares de apropiaciones se reconocerían en los relatos que refieren el milagro de la aparición de cruces grabadas en rocas (Irarrázaval 1980b). A su vez, podría considerarse a las cruces de calvarios de Ayquina, Caspana, Socaire y Toconce, comunidades surandinas de la provincia del Loa y el salar de Atacama, vestidas y adornadas con flores de papel, lanas de colores y otros ornamentos como parte también de un movimiento donde confluyen formas de decoración andinas e hispanas (Bustos 1999: 87; Castro 2009: 450) 25.

Ciertamente que las cruces protegen cosechas, animales, viviendas; a los pueblos y sus tierras, caminos, cerros grandes y pequeños. Fervor y temor están presenten en su homenaje pues pueden ayudar y también castigar si no se las cuida, agradece y celebra. Las cruces y sus fiestas hablan de pervivencias culturales, las que están en conexión con la vida histórica de los poblados y sus gentes, con los actos de sus memorias colectivas que producen sentidos, transmiten ideas y contenidos.

Aún hoy en día, la experiencia de los usos de las cruces en el contexto ritual etnográfico de Yucay (Urubamba, Departamento de Cuzco) permite situarlos en un contexto de producción de sentido en función de la representación de un acontecimiento histórico, en donde las cruces condensarían informaciones de importantes cambios sociales para la comunidad. La analogía de este proceso ritual respecto a las propiedades de las cruces del sistema del arte rupestre colonial, es la complejidad que alcanza la representación de la llamada cruz calvario. En efecto, de las cuatro cruces de Yucay, que representan las cuatro partes de la comunidad, y cada una de ellas con una producción de sentido particular, es la cruz calvario la que concentra el mayor poder (Molinié 1997).

\section{$*$ Discusión Final}

Volviendo al caso específico del sistema de arte rupestre colonial andino, se reconoce que el peso del imaginario religioso desplegado por la ortodoxia oficial, ya sea en el contexto de la palabra o de la imagen, tiene un peso es- pecífico en el proceso de control y dominación impuesto por el sistema colonial. Sin embargo, este no pasa en su totalidad al sistema del arte rupestre, el cual continúa funcionando al margen del poder colonial español. Se observa el traspaso de un repertorio acotado de motivos cristianos, los que se integran al sistema de arte rupestre en tanto nuevos significantes, siendo los jinetes, sombreros, iglesias, curas y cruces los más extendidos, aunque la cruz latina, junto a la cruz calvario y sus variantes, ocupan un lugar destacado dentro de ese sistema representacional.

Sólo a partir de investigaciones realizadas en el contexto del sistema de representación rupestre es posible reconocer que, a lo largo del período colonial, existirán al menos dos formas dominantes de representar la figura de la cruz ${ }^{26}$. Estas serían la cruz latina, de líneas simples, y la llamada cruz de atrio o de calvario, caracterizada por su pedestal. Se sugiere que las cruces latinas podrían ser representaciones más tempranas, mientras que las de atrio o calvario serían más tardías, y directamente relacionadas con procesos evangelizadores más agresivos y destructivos, posibles de ser datados a partir del mandato del virrey Toledo y su acción centralizadora, asociada además a la construcción de iglesias y capillas. En este contexto, el del arte rupestre, tanto la cruz latina como la cruz calvario, en su forma más convencional, sirven de soporte a una migración significante cuando se observan las múltiples o variadas formas que asumen estas cruces en el repertorio rupestre, esto, sin perder jamás el contenido de la imagen de la cruz latina, lo que hace pensar en una sutil o clara transformación de sentido y cuyo significado, al nivel actual de la investigación, escapa a su comprensión.

En este contexto de apropiación selectiva del referente, se observa en la cruz, provisionalmente al menos, dos comportamientos. Por un lado, su integración, en términos andinos o de la cultura propia, a sitios y paneles que, en muchos casos, vienen siendo usados desde tiempos prehispánicos; y por otro lado, su incorporación a sitios que

\footnotetext{
25 Véase nota 6.

26 Sin desconocer la amplia gama de variedades por agregaciones a estas dos formas básicas y que hacen distintiva a esta apropiación significante en el arte rupestre andino colonial.
} 
fueron construidos en el tiempo y espacio colonial, pero claramente ajenos a los espacios de dominación simbólica de los conquistadores europeos.

Si bien se constata el uso de la imagen de la cruz en una dimensión represiva en función del poder colonial, también se constata su presencia en contextos representacionales que se encuentran funcionando según la lógica de un lenguaje visual que tiene miles de años de funcionamiento en el espacio de los Andes del Sur. Lo interesante es que esos contextos de producción se ubican en ámbitos rurales, observándose allí, preliminarmente, algunos mecanismos diferenciados de apropiación selectiva. Uno de ellos sería el mecanismo representacional de la solidaridad diacrónica o bien de co-presentación del motivo cruz junto a motivos prehispánicos (Figura 3B). Otro de ellos sería el mecanismo representacional de trasladar un repertorio acotado de motivos indígenas al soporte de la cruz, obteniendo como resultado una cruz andino colonial que es reconocida e identificada como propia, y donde sus productores no desconectaron sus motivos del nuevo soporte, sino que lo llenaron de una nueva producción de sentido (Figuras 2A, 2B y $2 \mathrm{C}$ ). Un tercer movimiento o manifestación dice relación con la construcción de nuevos espacios sacralizados de arte rupestre y en un contexto colonial. Allí, los soportes se llenan de cruces cristianas, ya sea pintadas o grabadas, para dar cuenta de un nuevo imaginario dominante (Figura 3D).

Es posible afirmar entonces: que en ciertos espacios ru- rales, productores andinos coloniales están ejecutando apropiaciones selectivas de ciertos referentes icónicos cristianos, detectables en modos de construcción y contextos de circulación; que en el contexto del despliegue visual del evangelio, cuyo principal vehículo de difusión lo constituyeron la oralidad y el imaginario visual desplegado en iglesias y capillas de los principales repartimientos de indios, los ejecutantes no sólo están prefiriendo algunos referentes icónicos, sino que, se insiste en ello, también los están trabajando desde la cultura propia.

Cabe la pregunta, cesta migración o movimiento de repertorios icónicos selectivos hacia las cruces tendría un peso específico similar a los actos hispanos de levantar cruces grandes en espacios de wak'as poderosas?, ¿corresponderían estas migraciones a estrategias de continuidad e identidad de sus creencias y espacios sagrados y rituales? No parece aventurado proponer que estos desplazamientos se sitúan en el plano de las resistencias culturales, desplegándose "en forma de contrahegemonías" (Abercrombie 2006: 59). Respuestas y tensiones que no sólo resitúan el pasado andino precolonial, o bien, se apoyan en prácticas clandestinas. Por el contrario, el repertorio icónico selectivo es visible, puesto sobre la más importante figura de la cristiandad católica, la cruz. Allí se cruzan otras condiciones de producción, las que son posibles por la existencia de otras condiciones de recepción de la cruz, la que se considera también propia y querida.

\section{* Referencias citadas}

ABERCROMBIE, T. 2006. Caminos de la memoria y el poder. Etnografía e historia en una comunidad andina. IFEA-IEB-Asdi, La Paz.

ABSI, P. y P. CRUZ. 2006. La puerta de la wak'a de Potosí se abrió al infierno. La quebrada de San Bartolomé. Anuario del Archivo y Biblioteca Nacionales de Bolivia 12:3-40.

ACOSTA, J. de, S.J. 1590. Historia Natural y Moral de las Indias. Casa Juan de León, Sevilla.

ARENAS, M. A. 2011. Representaciones rupestres en los Andes Coloniales. Una mirada desde el sitio Toro Muerto (Comuna de La Higuera, Coquimbo, Chile). Tesis para optar al título de Antropólogo y grado de Licenciado en Antropología. Escuela de Antropología, Universidad Academia de Humanismo Cristiano, Santiago de Chile.
2013. Significantes rupestres coloniales del sitio Toro Muerto (Chile): Canon descriptivo y comentario preliminar. Boletín Sociedad de Investigación del Arte Rupestre de Bolivia (SIARB) 27: 87104.

ARENAS, M.A., P. LIMA, C. TOCORNAL y L. ALVARADO, 2015. El Arte Rupestre de Q'urini, Oruro - Bolivia. Estudio Preliminar. Boletín Sociedad de Investigación del Arte Rupestre de Bolivia (SIARB) $\mathrm{N}^{\circ}$ 29: 28-50. La Paz.

ARGUEDAS, J.M. 1989. Indios, mestizos y señores. Editorial Horizonte, Lima.

1998. Formación de una cultura nacional indoamericana, $6^{\mathrm{a}}$ ed. Siglo XXI editores, México. 
ARMAS, F. de. 1953. Cristianización del Perú (1532-1600). Escuela de Estudios Hispano-Americanos, Sevilla.

ARRIAGA, J. de. 1621. Extirpacion de la idolatria del Piru. Geronymo de Contreras, impresor de libros, Lima.

BARRIENTOS, L. 1984. La Cruz de Mayo: un ritual aymara en el interior de Arica. Revista Musical Chilena 38(162): 119-124.

BEDNARIK, R. 1992. Acerca de la motivación del re-uso del arte rupestre: un ejemplo del período colonial de Bolivia. Boletín SIARB. Contribuciones al Estudio del Arte Rupestre Sudamericano 3: 28-35.

BERENGUER, J. 1999. El evanescente lenguaje del arte rupestre en los Andes atacameños. En Arte Rupestre en los Andes de Capricornio, J. Berenguer y F. Gallardo (Eds.), pp. 9-56. Museo Chileno de Arte Precolombino, Santiago de Chile.

BITONTE, M.E. 2012. Huellas y proyecciones de un modelo epistemológico indicial. EAE, Editorial Académica Española, Berlín.

BUSTOS, A. 1999. Etnografía atacameña. Instituto de Investigaciones Antropológicas. Universidad de Antofagasta, Antofagasta.

CASTRO, V. 2009. De ídolos a santos. Evangelización y religión andina en los Andes del sur. DIBAM - Centro de Investigaciones Barros Arana, Santiago de Chile.

CHACAMA, J., L. BRIONES y G. ESPINOZA. 1988-1989. El arte mural en las iglesias coloniales de la Primera Región y la tradición pictórica andina en el extremo norte de Chile. Dialogo Andino 7/8: 102-120.

CHACAMA, J., L. BRIONES y C. SANTORO. 1992. Arte rupestre posthispano: Una aproximación al problema en el Norte de Chile. Arte Rupestre Colonial y Republicano de Bolivia y Países Vecinos. Boletín SIARB. Contribuciones al Estudio del Arte Rupestre Sudamericano 3: 168-171.

CLAROS, E. 1993. Santa Vera Cruz. Fiesta de la vida en el valle de Cochabamba. Balance y aportes bibliográficos para su estudio. Yachay-TM 9(10): 156-179.

DURÁN, J.G. 1982. El catecismo del III Concilio Provincial de Lima y sus complementos pastorales (1584-1585). Pontificia Universidad Católica Argentina, Buenos Aires.

EQUIPO PASTORAL DE LAMPA. 1980. Pastoral de la fiesta andina de la Cruz. Pastoral Andina 31: 17-29.

ESTENSSORO, J.C. 2003. Del paganismo a la santidad. La incorporación de los indios del Perú al catolicismo, 1532-1750. Pontificia Universidad Católica del Perú - IFEA, Lima.
GALLARDO, F., V. CASTRO y P. MIRANDA. 1990. Jinetes sagrados en el desierto de Atacama: un estudio de arte rupestre andino. Boletín del Museo Chileno de Arte Precolombino 4: 27-56.

GUTIÉRREZ, B. 2013. Evangelización colonial y religiosidad andina. Cultura, Ciencia y Tecnología, ASDOPEN/UNMSM 4: 29-38.

HERNÁNDEZ, M.I. 2006. Inkas y españoles a la conquista simbólica del territorio Humahuaca: sitios, motivos rupestres y apropiación cultural del paisaje. Boletín del Museo Chileno de Arte Precolombino 11(2): 9-34.

HIDALGO, J. 2012. Atacama colonial. De la conquista a la colonia. En Atacama, pp. 110-157. Museo Chileno de Arte Precolombino, Santiago.

HOSTNIG, R. 2004. Arte Rupestre Postcolombino de la Provincia de Espinar, Cusco Perú. Boletín SIARB 18: 40-64.

IRARRÁZAVAL, D. 1980a. Fiesta de la Cruz del campesinado de Misti. Pastoral Andina 31: 5-16.

1980b. Apuntes teológicos sobre la cruz andina. Pastoral Andina 31:30-50.

JIMÉNEZ DE MADARIAGA, C. 2011. Rituales festivos y confrontación social. Cruces de mayo de la provincia de Huelva. Gazeta de Antropología 27 (2), articulo 31. Disponible en: http://hdl. handle.net/10481/18640 (acceso en septiembre 2014).

MARTÍNEZ, J.L. 2009. Registros andinos al margen de la escritura: El arte rupestre colonial. Boletín del Museo Chileno de Arte Precolombino 14(1): 9-35.

2012. El virrey Toledo y el control de las voces andino coloniales. Colonial Latin American Review 21(2): 175-208.

MARTÍNEZ, J.L. y M. ARENAS. 2009. Problematizaciones en torno al arte rupestre colonial en las áreas Centro Sur y Meridional Andina. En Crónicas sobre la piedra. Arte Rupestre de Las Américas, M. Sepúlveda, L. Briones y J. Chacama (Eds.), pp. 129-140. Ediciones Universidad de Tarapacá, Arica.

Iglesia en la piedra: representación rupestre y evangelización en los andes del sur. En La vitalidad de las voces indígenas: arte rupestre del contacto y en sociedades coloniales, F. Berrojalbiz (Ed.). UNAM, Oaxaca (en prensa).

MEGE, P. 2000. Originales contra la fuerza. Boletín de la Sociedad Chilena de Arqueología 30: 41-47.

MEGE, P y F. GALLARDO. 2006. Soluciones semióticas y pinturas rupestres en la localidad del río Salado (Desierto de Atacama, Norte de Chile). Ms. 
MILLONES, L. 2007. Taki Onqoy: De la enfermedad del canto a la epidemia (con las Informaciones de Cristóbal de Albornóz). DIBAM - Centro de Investigaciones Barros Arana, Santiago de Chile.

MOLINIÉ, A. 1997. Buscando una historicidad andina: una propuesta antropológica y una memoria hecha rito. En Arqueología, antropología e historia en los Andes. Homenaje a María Rostworowski, R. Varon y J. Flores (Eds.), pp. 691-708. IEP - Banco Central de Reserva del Perú, Lima.

1999. Dos celebraciones "salvajes" del cuerpo de Dios (Los Andes y La Mancha). En Celebrando el cuerpo de Dios, A. Molinié(Ed.), pp. 245-282. Pontificia Universidad Católica del Perú, Lima.

MORAGA, C. 1996. Manifestaciones rupestres en el tramo bajo de la quebrada de Tambillo, Provincia de Iquique, I Región. Chungara 28: 241-252.

NIEMEYER, H. 1968. Petroglifos del río Salado o Chuschul (San Pedro de Atacama, Dpto. del Loa, Prov. De Antofagasta, Chile). Boletín de Prehistoria de Chile 1(1): 85-92.

OCHOA, V. 1976. La fiesta de Santa Cruz. Boletín Ocasional 32: 1-13.

PEÑA MONTENEGRO, A. de la. 1771. Itinerario para párrocos de indios en que se tratan las materias más particulares tocantes á ellos para su buena administración. Oficina de Pedro Marín, Madrid.

PÉREZ, J. 1998. La salud social. De la socioeconomía al comunitarismo. Trotta, Madrid.

PIZARRO, P. 1978 [1571]. Relación del descubrimiento y conquista del Perú. Pontificia Universidad Católica del Perú, Lima.

QUEREJAZU, R. 1992. Introducción. Boletín SIARB. Contribuciones al Estudio del Arte Rupestre Sudamericano 3: 6-27.

RICARDO, A. 1585. Tercero Catecismo, y exposicion de la doctrina christiana por sermones. Lima. Citado por Valenzuela, J. 2006. "que las ymagenes son los ydolos de los christianos". Imágenes y reliquias en la cristianización del Perú. Jahrbuch für Geschichte Lateinamerikas 43: 41-66, Köln/Weimar/Wien.

SANHUEZA, C. 2005. Espacio y tiempo en los límites del mundo. Los incas en el despoblado de Atacama. Boletín del Museo Chileno de Arte Precolombino 10(2): 51-77.
SOLAR, C. del y R. HOSTNIG, 2004. Litograbados indígenas en la arquitectura colonial del departamento de Cusco. Avances en su registro y documentación. Actas del Primer Simposio de Arte Rupestre: 285-339.

STRECKER, M y F. TABOADA. 2004. 'Aymara' Rock Art of Lake Titicaca. Rock Art Research 21(2): 111-125.

TOLEDO, F. de. 1924 [1570-1575]. Libro de la Visita general. Citado por Martínez, J.L. 2012. El virrey Toledo y el control de las voces andino coloniales. Colonial Latin American Review 21 (2): 175-208, Albuquerque.

VALENZUELA, J. 2006. Imágenes y reliquias en la cristianización del Perú. Jahrbuch für Geschichte Lateinamerikas 43: 41-66.

2007. Confesando a los indígenas. Pecado, culpa y aculturación en América colonial. Revista Española de Antropología Americana $37(2): 39-59$.

2012. La cruz en la cristianización jesuita de Chile meridional: Signo, significados y paradoja (1608-1655). En La Mediación lingüístico-cultural en tiempos de Guerra: Cruce de miradas desde España y América, G. Payàs y J.M. Zavala (Eds.), pp. 189-216. Ediciones Universidad Católica de Temuco, Temuco.

VAN KESSEL, J. 1996. Los aymaras contemporáneos de Chile. En Culturas de Chile Etnografía. Sociedades indigenas contemporáneas y su ideología, J. Hidalgo, V. Schiappacasse, H. Niemeyer, C. Aldunate y P. Mege (Eds.), pp. 47-109. Editorial Andrés Bello, Santiago de Chile.

VARGAS, R. S.J. (Ed.). 1951, 1952, 1954. Concilios Limenses (15511772), 3 tomos. Imprimatur, Lima.

VARON, R. 1990. El Taki Onqoy: las raíces andinas de un fenómeno colonial. En El retorno de las huacas, L. Millones (Comp.), pp. 331-405. IEP - Sociedad Peruana de Psicoanálisis, Lima.

VERÓN, E. 1988. La semiosis social. Gedisa, Barcelona.

ZUIDEMA, T. 1999. La fiesta del Inca. En Celebrando el cuerpo de Dios, A. Molinié (Ed.), pp. 191-243. Pontificia Universidad Católica del Perú, Lima. 